\title{
Editorial
}

\section{European Thyroid Association Guidelines on L-T4 + L-T3 Combination for Hypothyroidism: A Weary Step in the Right Direction}

\author{
Petros Perros \\ Department of Endocrinology, Royal Victoria Infirmary, Newcastle upon Tyne, UK
}

This issue of the European Thyroid Journal features the European Thyroid Association (ETA) guideline on the use of L-T4 + L-T3 (levothyroxine + liothyronine) in the treatment of hypothyroidism [1]. Some time ago, the first author of the guideline invited me to speak at the annual ETA meeting on the very same topic. It was 5 years after the Bunevicius paper [2], which had already been followed by several larger studies aiming to address the question of whether combination treatment was more effective than L-T4 monotherapy. The newer studies at the time [3-6] had confirmed my own personal clinical experience that tired patients on L-T4 continued to be tired patients on L-T4 + L-T3 . I made a few rather cynical remarks during my presentation, which got me some laughs by the audience. Unaware that I was speaking to anyone but colleagues, I was confronted at the end of my talk by an angry lady, who turned out to be a patient representative. She made sure I noted that her views and personal experience were very different to what I had portrayed. I had unintentionally offended a hypothyroid patient, which I regretted terribly, but after a lengthy discussion with her, which continued with occasional emails for several months, I was delighted to be asked to act as medical advisor for her thyroid patient-led organization. We remain friends and respect each other, though our views are still different.

Eight years on, the ETA draft guideline on L-T4 + L-T3 treatment was posted on the ETA website for wider con- sultation before its publication. I submitted a lengthy, critical response, which landed me an invitation by the first author of the guideline for this editorial. Voicing opinions on the subject of L-T4 + L-T3 therapy seems a sure way of getting oneself into trouble.

Is there more to say about the treatment of hypothyroidism and the L-T4 + L-T3 story? Thirteen years on since the Bunevicius paper, after 11 randomized controlled studies and a meta-analysis [7], the evidence seems to be pointing in the same direction: there is a consistent placebo effect, but in the end, the outcome is the same. Alternative explanations are that the magnitude of the effect of L-T4 + L-T3 treatment is extremely small and would require a larger sample size to demonstrate in a clinical trial, or it is only beneficial in a very small subpopulation of patients with hypothyroidism, or the delivery of T3 is suboptimal.

The ETA guideline begins with a comprehensive and balanced review of the available evidence that dissects out the weaknesses and remaining areas of uncertainty. And there are plenty: the target patient population, frequency of T3 administration, ratio of T4 to T3 dosing and serum levels achieved are some of them, as well as the fact that some studies did show benefit in certain domains of psychological and cognitive function.

Patients with treated hypothyroidism frequently experience residual symptoms, express lack of satisfaction with their treatment, and seek explanations and alterna-

\section{KARGER}

Fax +4161306 1234

E-Mail karger@karger.ch

www.karger.com
(C) 2012 European Thyroid Association

Published by S. Karger AG, Basel

2235-0640/12/0012-0051\$38.00/0

Accessible online at:

www.karger.com/etj
Dr. Petros Perros

Department of Endocrinology

Elliott Building, Royal Victoria Infirmary

Newcastle upon Tyne, NE1 4LP (UK)

Tel.+44 191282 0590, E-Mail petros.perros@ncl.ac.uk 
tives to L-T4. In Europe, as many as 1 million patients may fall in this category, though the aetiology of this phenomenon is unclear. Large population studies have shown that patients taking L-T4 often have abnormal thyroid biochemistry [8], either due to compliance issues or inadequate medical supervision. How clinicians manage patients on thyroid hormone replacement who continue to have symptoms, varies widely. Exclusion of other diagnoses is a sensible starting point, but anecdotally it appears not to be done systematically or at all. Adding T3 to L-T4 is an avenue which some physicians pursue, an approach that is often driven by patients themselves. Prescription habits for T3 differ in Europe. Data from the UK indicate that $0.3 \%$ of all thyroid hormone prescriptions were for T3 [9], while in a district in Germany, 8.9\% of thyroid hormone prescriptions included T3 [10]. So, the clinical problem of 'on L-T4 and still tired' is real and widespread, cannot be ignored, and clinical practice is variable, which leads to the conclusion that there is a need for guidance.

Is there evidence-based advice that clinicians treating hypothyroidism can draw from this guideline? The document quite sensibly advises that firstly, diagnoses other than hypothyroidism should be excluded. It also emphasizes the importance of optimizing L-T4 therapy, as some patients will respond to fine adjustment of L-T4 therapy. This is all sensible, good medicine, nothing new but worth flagging up and useful for the inexperienced or the non-specialist. Having reviewed the very extensive evidence meticulously and arrived at the conclusion that there is insufficient evidence that L-T4 + L-T3 combination therapy is better than T4 monotherapy, the guideline concludes and recommends that T4 monotherapy should be the standard treatment for hypothyroidism. This recommendation is given the highest possible grading $(1 /+++)$. Then comes a surprise. The guideline states that L-T4 + L-T3 combination therapy may be considered in patients on L-T4 who have persistent symptoms despite optimal L-T4 replacement on an 'experimental' basis. The grading given by the authors for this recommendation is $2 /+00$, i.e. this is a 'suggestion' based on low level of evidence. This latter recommendation is at odds with other published guidelines [11-13].

The lack of positive evidence and indeed the presence of overwhelming negative evidence of course does not exclude the plausibility of the proposition that combination therapy may be better than L-T4 alone. Flight by man, pioneered by Icarus with catastrophic results, would have seemed futile if not suicidal, until the Wright brothers proved that it could be done successfully and safely. So, even the most vociferous opponents of L-T4 + L-T3 ther- apy must keep an open mind about the enigma of thyroid hormone replacement. The guideline highlights the reasons why this chapter in the history of thyroidology is not yet closed and paves the way for formulating additional research questions, which may help us get closer to understanding and improving thyroid hormone replacement.

Doctors are the archetypal pragmatists, and it seems that the authors of the ETA guideline have taken such an approach. Patients demand L-T4 + L-T3 therapy, some physicians (whether we like it or not) do prescribe it, but with unclear indications and widely differing dosing schedules. At the very least, this guideline will help those physicians whose practice it is already to prescribe L-T4 + L-T3 to base their prescribing on a rational, pharmacologically sound, though not necessarily evidence-based footing. Then there are those of us who neither prescribe nor recommend L-T4 + L-T3. Like most in the thyroid community, we were excited by the New England Journal of Medicine publication in 1999 [2] showing benefits of L-T4 + L-T3 combination therapy, changed our practice to L-T4 + L-T3 prescribing, were disappointed by our own observations, which were later confirmed by many randomized controlled trials, then reverted to L-T4 monotherapy. For that breed of thyroidologists, this guideline feels like a Pandora's box. What additional baggage will 'experimenting' with L-T4 + L-T3 therapy carry when the placebo effect wanes? Not unreasonably, patients may wish to experiment further with different ratios of T4/T3 dosages. Should the physician lead, collude, support or disengage when that scenario inevitably unfolds? How easy will it be to judge if treatment has been effective when the outcome is so vague? Will this lead to a roller coaster of raising the hopes and expectations of distressed patients only to be let down by the lack of response? How on earth do we achieve the desired T4/T3 ratios when constrained by the narrow range of dosages of $\mathrm{T} 3$ and $\mathrm{T} 4$ available by manufacturers? How useful are the formulae provided by the guideline for estimating the dose of $\mathrm{T} 4$ and T3 in clinical practice? A glance at some of the forums and blogs on the mass media alarmingly reveals that some patients who have no or a partial response to $\mathrm{L}-\mathrm{T} 4+\mathrm{L}-\mathrm{T} 3$ go on to pursue other types of replacement treatments including glucocorticoid, testosterone and growth hormone based on anecdotes of miraculous recovery from incapacitating fatigue, 'brain fog' and obesity. How will this change in clinical practice affect expectations by those patients who do not even have hypothyroidism but complain of the symptoms of hypothyroidism and demand thyroid hormone treat- 
ment? These concerns may be exaggerations. After all, thyroidologists should be used to the concept of a therapeutic trial. A trial of L-T4 for patients with subclinical hypothyroidism is an accepted and practiced strategy, which is endorsed by guidelines of professional organizations $[11,12]$, and the experience is certainly not that of an overflowing Pandora's box. However there are important differences between a trial of L-T4 + L-T3 for hypothyroidism and a trial of L-T4 for subclinical hypothyroidism. The evidence for a beneficial effect for the latter is more sound [14], for the former lacking. L-T4 treatment for subclinical hypothyroidism does no harm and probably does some good in reducing cardiovascular risk factors [15]. L-T4 + L-T3 treatment may have undesirable long-term effects on the heart and bones, optimal L-T4 replacement does not. For these reasons I remain skeptical about the wisdom of a trial of L-T4 + L-T3 treatment and the impact it will have on our practice.

What the ETA guideline does promote is that thyroid experts must engage with the sector of thyroid patients who suffer unexplained symptoms. This is commendable. Patients deserve access to the best quality of information about their condition and how it applies to their own individual circumstances. They need to understand the advantages and downsides of different strategies that may be used to address their symptoms. They must not be left alone to grapple with the mountains of misinformation that seem to abound in the mass media, generously provided by self-appointed experts with unspecified motives. Some patients are so driven by desperation that they are willing to take any risk and hang on to anything that offers hope. They are vulnerable and prone to exploitation. They will obtain supplies of T3 if not by prescription, by mail order, and will use it. It can be argued that even those thyroidologists who are unconvinced by the L-T4 + L-T3 approach and reluctant to incorporate it in their clinical practice have an obligation at the very least to counsel patients and supervise their combination treatment, if the patient choses to take it. The guideline rightly recommends that managing the patient on thyroid hormone replacement who has residual symptoms should be undertaken only by clinicians who are appropriately trained in thyroidology. This is useful and important and to some extent will help safeguard vulnerable patients from unaccredited practitioners.

On balance, I cautiously welcome the ETA guideline. It is patient centred and will encourage clinicians and disenfranchised patients to engage with each other. This can only be a good thing. The authors have had the courage to take a stance on L-T4 + L-T3 and that is admirable,

though it will be perceived as controversial by many of their peers for not being based on evidence. In my view, the proposition to 'experiment' with a trial of L-T4 + L-T3 treatment comes with a responsibility that befalls upon the ETA and clinicians who adopt the guideline: to audit it and report back over the next 1-2 years. The thyroid community needs to know: (1) what proportion of patients presenting with unresolved symptoms while on L-T4 have an alternative diagnosis; (2) how often are the target biochemical parameters achieved on L-T4 + L-T3 using the recommended formulae; (3) does the conversion from L-T4 monotherapy to combination L-T4 + L-T3 cause periods of instability of the thyroid status; (4) how many additional consultations and measurements of thyroid function are generated by conversion to L-T4 + L-T3; (5) is L-T4 + L-T3 associated with documented episodes of cardiac arrhythmias or other adverse effects; (6) what proportion of patients decide to abandon the L-T4 + L-T3 'experiment', and finally and most importantly, (7) what is the patients' opinion and level of satisfaction with the 'experiment'? This is not difficult to do and although it will never answer the important remaining questions about the L-T4 + L-T3 story, it will be hugely valuable for everyday management of patients with hypothyroidism.

I expect the guideline will change our practice and will stimulate more research on this fascinating topic. I also foresee that the views expressed in this editorial will drive me even into deeper trouble, for which I have no hesitation in blaming the first author of the guideline.

\section{Disclosure Statement}

Nothing to declare.

References

\footnotetext{
1 Wiersinga WM, Duntas L, Fadeyev V, Nygaard B, Vanderpump MPJ: 2012 ETA Guidelines: the use of L-T4 + L-T3 in the treatment of hypothyroidism. Eur Thyroid J 2012;1:55-71

-2 Bunevicius R, Kazanavicius G, Zalinkevicius R, Prange AJ Jr: Effects of thyroxine as compared with thyroxine plus triiodothyronine in patients with hypothyroidism. N Engl J Med 1999;340:424-429.

-3 Saravanan P, Chau WF, Roberts N, Vedhara K, Greenwood R, Dayan CM: Psychological well-being in patients on 'adequate' doses of L-thyroxine: results of a large, controlled community-based questionnaire study. Clin Endocrinol (Oxf) 2002;57:577-585.
} 
-4 Clyde PW, Harari AE, Getka EJ, Shakir KM: Combined levothyroxine plus liothyronine compared with levothyroxine alone in primary hypothyroidism: a randomized controlled trial. JAMA 2003;290:2952-2958.

-5 Sawka AM, Gerstein HC, Marriott MJ, MacQueen GM, Joffe RT: Does a combination regimen of thyroxine (T4) and 3, 5, 3'triiodothyronine improve depressive symptoms better than $\mathrm{T} 4$ alone in patients with hypothyroidism? Results of a double-blind, randomized, controlled trial. J Clin Endocrinol Metab 2003;88:4551-4555.

-6 Walsh JP, Shiels L, Lim EM, Bhagat CI, Ward LC, Stuckey BG, Dhaliwal SS, Chew GT, Bhagat MC, Cussons AJ: Combined thyroxine/ liothyronine treatment does not improve well-being, quality of life, or cognitive function compared to thyroxine alone: a randomized controlled trial in patients with primary hypothyroidism. J Clin Endocrinol Metab 2003;88:4543-4550.

7 Wiersinga WM: Do we need still more trials on T4 and T3 combination therapy in hypothyroidism? Eur J Endocrinol 2009;161:955959.
8 Ladenson PW: Psychological wellbeing in patients with hypothyroidism. Clin Endocrinol (Oxf) 2002;57:575-576.

-9 Mitchell AL, Hickey B, Hickey JL, Pearce SH: Trends in thyroid hormone prescribing and consumption in the UK. BMC Public Health 2009;9:132-211.

10 Hannemann A, Friedrich N, Haring R, Krebs A, Völzke H, Alte D, Nauck M, Kohlmann T, Schober H-C, Hoffmann W, Wallaschofski $\mathrm{H}$ : Thyroid function tests in patients taking thyroid medication in Germany: results from the population-based Study of Health in Pomerania (SHIP). BMC Res Notes 2010;3:227-231.
Baskin HJ, Cobin RH, Duick DS, Gharib H, Guttler RB, Kaplan MM, Segal RL, American Association of Clinical Endocrinologists: American Association of Clinical Endocrinologists medical guidelines for clinical practice for the evaluation and treatment of hyperthyroidism and hypothyroidism. Endocr Pract 2002;8:457-469.

12 Muller AF, Berghout A, Wiersinga WM, Kooy A, Smits JW, Hermus AR, working group Thyroid Function Disorders of the Netherlands Association of Internal Medicine: Thyroid function disorders - Guidelines of the Netherlands Association of Internal Medicine. Neth J Med 2008;66:134-142.

13 Royal College of Physicians: The Diagnosis and Management of Primary Hypothyroidism. http://www.british-thyroid-association. org/news/Docs/hypothyroidism_statement. pdf.

14 Razvi S, Weaver JU, Pearce SH: Subclinical thyroid disorders: significance and clinical impact. J Clin Pathol 2010;63:379-386.

-15 Duntas LH, Biondi B: New insights into subclinical hypothyroidism and cardiovascular risk. Semin Thromb Hemost 2011;37:27-34.

\section{Note}

For the article '2012 European Thyroid Association Guidelines for Metastatic Medullary Thyroid Cancer' by Schlumberger M, Bastholt L, Dralle H, Jarzab B, Pacini F, Smit JWA, The European Thyroid Association Task Force (Eur Thyroid J 2012;1:5-14), the following disclosures have been made:

M. Schlumberger (Advisory Board member of Amgen, Astra Zeneca, Exelixis, Eisai); L. Bastholt (Advisory Board member of Astra Zeneca);

H. Dralle (none);

B. Jarzab (Advisory Board member of Astra Zeneca, consultant of Exelixis);

F. Pacini (none);

J.W.A. Smit (ad-hoc advisor to Genzyme and Bayer). 